\title{
Measuring administrative integration of disease control programmes within health systems: a case study of HIV monitoring and evaluation in South Africa
}

\author{
Mary Kawonga ${ }^{1 *}$, Sharon Fonn ${ }^{2}$, Duane Blaauw ${ }^{3}$ \\ From Health Services Research: Evidence-based practice \\ London, UK. 1-3 July 2014
}

\section{Background}

In South Africa, integrating the management of health services at a decentralized district level within the authority of general health service (GHS) managers is a reform priority. The reforms promote administrative integration, i.e. transfer of administrative authority over disease control programmes (DCPs) from DCP managers to GHS managers and re-defining DCP manager roles from implementation to specialist support. Historically DCP activities at district level fall under the control of DCP managers and dedicated programme monitoring and evaluation (M\&E) systems limit GHS managers' access to data that they need for integrated management. Given the reform focus on administrative integration, research is needed to measure the extent to which GHS managers exercise administrative authority over DCP functions. This study addresses this gap, using the HIV programme M\&E function as an exemplar.

\section{Materials and methods}

This study was conducted in two of South Africa's nine provinces, involving interviews with 51 GHS and DCP managers. We adapted and applied the concept of 'decision-space' (traditionally used to measure transfer of administrative authority from higher to lower level managers). We defined 'exercised authority' over the HIV $M \& E$ function as performance of tasks to: a) oversee the production of HIV information (HIV data collection, collation and analysis), and b) use HIV information for monitoring services. Participants reported whether they

'Department of Community Health, Wits School of Public Health, Faculty of Health Sciences, University of the Witwatersrand, Johannesburg, South Africa Full list of author information is available at the end of the article performed specific tasks within each M\&E domain (data collection, collation, analysis and use). Responses were scored within each domain and summed scores categorised as 'low', 'medium', or 'high' degree of exercised authority. We applied ordinal logistic regression to evaluate associations between various variables (actor type [DCP or GHS], capacity [training and experience] and HIV M\&E knowledge) and the degree of exercised authority. We also assessed whether DCP actors play expected specialist support roles.

\section{Results}

Relative to DCP managers, GHS managers had lower M\&E knowledge and exercised greater authority over the production of HIV information but less over using HIV information. Higher HIV M\&E knowledge was associated with higher degrees of HIV information use. DCP and GHS manager roles overlap; few DCP managers played their expected specialist support role.

\section{Conclusions}

There has been transfer of authority for overseeing the production of HIV information from DCP to GHS managers, but DCP managers still control the use of HIV information and rarely play expected specialist support roles. Actions are needed to integrate the use of DCP information within GHS managers' roles.

\section{Authors' details}

${ }^{1}$ Department of Community Health, Wits School of Public Health, Faculty of Health Sciences, University of the Witwatersrand, Johannesburg, South Africa. ${ }^{2}$ Wits School of Public Health, Faculty of Health Sciences, University of the Witwatersrand, Johannesburg, South Africa. ${ }^{3}$ Centre for Health Policy, Wits 
Published: 7 July 2014

doi:10.1186/1472-6963-14-S2-P62

Cite this article as: Kawonga et al:: Measuring administrative integration

of disease control programmes within health systems: a case study of

HIV monitoring and evaluation in South Africa. BMC Health Services

Research 2014 14(Suppl 2):P62.

Submit your next manuscript to BioMed Central and take full advantage of:

- Convenient online submission

- Thorough peer review

- No space constraints or color figure charges

- Immediate publication on acceptance

- Inclusion in PubMed, CAS, Scopus and Google Scholar

- Research which is freely available for redistribution

Submit your manuscript at www.biomedcentral.com/submit
() Biomed Central 